\title{
A Comparative Analysis of Common E-Portfolio Features and Available Platforms
}

\author{
Retta Sweat-Guy \\ Fayetteville State University, \\ Fayetteville, NC, USA \\ Rguy@uncfsu.edu
}

\author{
Nicole A. Buzzetto-More \\ University of Maryland Eastern \\ Shore, Princess Anne, MD, USA \\ Nabuzetto-more@umes.edu
}

\begin{abstract}
Assessment of student learning outcomes plays an important role in educational effectiveness, improvement, and sustainability that is increasingly being recognized and required by accrediting bodies (Buzzetto-More, 2006; Haken, 2006). A form of performance-based assessment that is growing in popularity and is heralded for its purposeful, dynamic, and integrated nature is the portfolio (Cooper, 1999; ePort, 2003; Paulson, Paulson, \& Meyer, 1991).

Electronic portfolios encourage students to engage in self reflection by providing a broad range of means for expressing the total learning experience as linked to standards and learning outcomes (AAHE, 2001; Barett, 2004; ePort, 2003; Martell \& Calderon, 2005; Popper, 2005). They are an effective form of assessment that encourages students and educators to examine skills that may not be otherwise accessed using traditional means such as higher order thinking, communications, and collaborative abilities (Buzzetto-More, 2006; Wright, 2004).

Electronic portfolios can be created using tools ranging from off-the-shelf generic software applications to widely available systems. This paper will focus on the latter by investigating the eight most widely available systems and by providing a detailed examination of their platform features. A matrix has been provided that offers a side-by-side comparison of the platforms by a variety of features that include: learning outcomes, rubrics, storage, support, assessments, surveys, advisement, communication, collaboration, data collection/reporting, intended user, supporting file types, pricing structure, and accessibility.
\end{abstract}

Keywords: electronic portfolios, authentic assessment

\section{Literature Review}

Haken (2006) explained that assessment is an integral part of assuring that an educational institution achieves its learning goals, as well as a crucial means of providing the essential evidence

Material published as part of this publication, either on-line or in print, is copyrighted by the Informing Science Institute. Permission to make digital or paper copy of part or all of these works for personal or classroom use is granted without fee provided that the copies are not made or distributed for profit or commercial advantage AND that copies 1) bear this notice in full and 2) give the full citation on the first page. It is permissible to abstract these works so long as credit is given. To copy in all other cases or to republish or to post on a server or to redistribute to lists requires specific permission and payment of a fee. Contact Publisher@InformingScience.org to request redistribution permission. necessary for seeking and maintaining accreditation and validation. Ridgway, McCusker, and Pead (2004) discuss what they refer to as e-assessment. They explain that technology is pervasive in professional practice and educational effectiveness and as a result should play an important role in assessment programs. They also assert that eassessment is flexible and supports the assessment of higher order thinking, 
social skills, and group work through such means as electronic portfolios.

It is important to measure knowledge gained; however, measuring knowledge is not sufficient to determine teaching and learning effectiveness (Haken, 2006). As a result, assessing students' critical thinking and ability to engage in knowledge application has been found to be crucial to successful assessment programs and one that can be facilitated with, and satisfied by, the use of student learning portfolios (Wright, 2004).

A number of educators have defined student learning portfolios. An excellent description was offered by Paulson, Paulson and Meyer (1991) who described a portfolio as a meaningful collection of student work that demonstrates progress and/or mastery guided by standards and includes evidence of student self-reflection. Abrenica (1996) defined a portfolio as a collection of student achievement artifacts created during a period of time that serve as authentic assessment tools used to evaluate student learning. Weidmer (1998) explained that electronic portfolios are a digital collection of student work that demonstrates individual efforts, progress, and achievements in designated areas. According to Buzzetto-More (2006) electronic portfolios have a number of advantages over those that are paper based as they support: a greater variety of artifacts and allow for increased learner expression; are dynamic and multimedia driven; accessible by a large audience; contain meta-documentation; easy to store; and may serve to promote a student academically or professionally.

According to Lorenzo and Ittelson (2005b) electronic portfolios are the biggest innovation in educational technology since the introduction of course management systems and they show promise across disciplines, institutions, and applications. Jafari (2004) explains that academic leaders are excited by electronic portfolios because they offer a new environment to demonstrate and assess student learning and the mapping of outcomes in accordance with established objectives. Electronic portfolio adoption is on the rise according to Casey Green's 2004 Campus Computing Survey which found that the number of institutions offering electronic portfolios doubled from the previous year (Batson, 2005).

According to the American Association of Higher Education (2001), portfolios have a broad application in a variety of contexts for the collection of meaningful evidence about learning outcomes that can enhance the effectiveness of student assessment programs. Popper (2005) reported that portfolios can be used to assess learning-outcome achievement as well as to diagnose curriculum deficiencies that require improvement. He explained that portfolios should include a variety of samples of student work so that learners and educators have ample opportunity to assess learning mastery. Chun (2002) explains that the portfolio building process encourages students to engage in structured reflection as well as to see how learning translates into productive practice.

Helen Barrett, who has published numerous papers over the past decade on the uses of electronic portfolios in education, explained, in 2000, that electronic portfolios, due to their dynamic nature, are able to illustrate relationships by demonstrating how student learning and achievement relates to learning goals and the ability of a program to effectively communicate these goals to learners (Barrett, 2000). As a model for learner-centered classrooms, portfolios provide opportunities for students to become active learners as they set goals for learning, engage in self-reflections, review goals, and assume responsibility for their own learning (Barrett, 2004).

Value-added assessment demonstrates the progress of student learning throughout curriculum (Martell, 2005). Electronic Portfolios built throughout a student's time in an academic program are an excellent form of value added assessment that can be a strong indicator to both the student and the academic institution of learner growth and achievement (Popper, 2005). 
According to the ePortConsortium (2003) the benefits of electronic portfolios in education are numerous, serving a number of purposes and stakeholders. In a 2003 whitepaper, the ePortConsortium explained that student portfolios not only encourage meta-cognition; but also help students develop organizational skills; recognize skills, abilities, and shortcomings; showcase talents; assess academic progress; demonstrate how skills have developed over time; make career decisions; demonstrate that one has met program or certification requirements; and promote themselves professionally. The paper notes that electronic portfolios are easily accessible and can be shared and reviewed by designees regardless of geography. The ePortConsortium refers to traditional assessment measures such as test scores and transcripts as "one dimensional" and says that portfolios offer an alternative approach that is more authentic and student centered. As a result, they assert that electronic portfolios are the most reflective means of expressing a broad range of a student's total learning experience that can include important information and artifacts that may not be considered when traditional assessment measures are applied. Additionally, the consortium notes that, electronic portfolios can link to standards, incorporate rubric analysis, work in conjunction with assessment databases, and be communicated to external evaluators.

In 1993 the United States Office of Educational Research and Improvement (OERI) stated that performance assessments should be used to augment or replace norm-referenced tests at all educational levels and included the use of portfolios as an effective means of quality performance assessment (1993b). The OERI noted that portfolios are an effective means of performance assessment that help communicate expectations to learners (1993a).

According to Lorenzo and Ittelson (2005a) institutions must decided what type of electronic portfolio best suits their needs. They have identified four types of electronic portfolios: homegrown, open source, commercially available, and software generated (2005b). A homegrown portfolio is one that is created by an institution and is customized to meet unique institutional needs; however, the creation process can be expensive, time consuming, and burdensome. An open source portfolio is one that is publicly available at no charge and where the source code is available for customization. Open source portfolios are risky as the institution incurs costs, upgrades may not be timely, and the initiative may end disbanding the community of users. Commercial portfolios available for purchase from vendors are well developed and include technical support; however, they can be costly to purchase and the support service may be of poor quality and/or expensive. The final type of portfolio is the one that uses common tools such as Front Page or PowerPoint to support the creation of electronic portfolios. These are inexpensive; however, they are the most difficult for students to create and may be overly simplistic in structure.

Cooper (1999) identified six considerations at the institutional level that occur when creating a student portfolio assessment project: identification of skill areas, design of measurable outcomes, identification of learning strategies, identification of performance indicators, collection of evidence, and assessment.

Love and Cooper (2002) explained that electronic portfolio systems should have their designs influenced more by educational goals rather than technical issues. They suggest that an electronic portfolio system should include a full suite of software, templates, a means for students to bring in materials built elsewhere, and reflective student commentaries that serve as metadocumentation.

Jafari (2004) asserts that electronic portfolios have different meanings among potential users. Provosts, deans, chairs, career centers, faculty, students, accrediting bodies, and professional organizations all perceive different functional requirements of an electronic portfolio system. As a result, Jafari recommends that during the electronic portfolio creation process that the system's future users, potential benefits, and versatility be considered. 
Successful examples of electronic portfolio projects can be found in both K-12 and higher education. For example, New High Tech High School in Napa, California involves students in longterm technology-dependent portfolio projects (Page, 2006) and the business program at Merrimack College has students engaged in an ongoing portfolio building process throughout their time in the program where students revisiting their portfolio will be able to observe their academic and professional growth (Popper, 2005).

Many teacher education programs have successfully incorporated electronic portfolios into their curricula as a means to satisfy current U.S. National Council for Accreditation of Teacher Education (NCATE) standards that require student demonstration of learning outcomes, the collection of meaningful evidence about these outcomes, as well as the use of technology as an integral part of the teacher education process (National Council for Accreditation of Teacher Education [NCATE], 1997). The examination of how electronic portfolios have benefited assessment in pre-service teacher education across disciplines is useful in informing the other curriculum areas that also pose to benefit from electronic portfolios in the future such as information systems, communications, business, and etcetera.

Bartell, Kaye, and Morin (1998), who examined the use of portfolios in teacher education in the State of California, found that the use of portfolios is a highly effective way for teacher candidates to present artifacts and evidence demonstrating the mastery of standards and referred to portfolios as "elevating the dialogue about teaching practice" (p. 131). Similar findings were echoed by Anderson and DeMeulle (1998) who surveyed 127 teacher educators throughout the United States regarding the use of portfolios in new teacher preparation finding high levels of satisfaction with regard to the effectiveness of student portfolios in teacher education programs. Finally, Montgomery (2002) found digital portfolios in teacher education to be "powerful tools" for encouraging reflective thinking when influenced by sound developmental principles and strong institutional guidance and support. He said that digital portfolios help both students and experienced educators analyze the professional growth and preparedness of students.

\section{Features}

There are a variety of features that can commonly be found in electronic portfolio systems. When selecting an electronic portfolio system for adoption, it is important to understand the possible features as well as to determine which are necessary to fit the long and short term needs of a particular institution. These features include: advisement, artifacts, assessment, communication and collaboration, course management, evaluations/observations, hosting and support, intended user and user type, learning outcomes, reflections, reporting, rubrics, sharing of information, surveys, templates, and technological requirements.

\section{Advisement}

Some electronic portfolio systems have built-in features for student advisement. This feature enables the advisors to guide students in their course selection process, track student progress towards graduation requirements, make both discrete and public notes on the students progress, facilitate communications between advisor and advisee, ensure that requisites have and/or are being met, print reports, and make key advising decisions.

\section{Artifacts}

Artifacts are the items that students select to demonstrate the satisfaction of learning goals. Some systems allow the types of artifacts that may be chosen by students to be predefined by the instructor or the student is given the freedom to make such a determination. Whereas some systems allow multiple artifacts per learning outcome some place limitations. Additionally, electronic 
portfolio systems may or may not limit the types of files and/or file sizes that can be included into student portfolios.

\section{Assessment}

Computerized delivery and analysis of diagnostic or traditional testing is increasing in popularity. According to Hamilton and Shoen (2005), web-based testing has significant advantages in the areas of cost, ease of use, reliability, replicability, scoring, aggregating results, and data management. Hamilton and Shoe also argue that digital assessment measures can score themselves with great reliability and no subjectivity while making data available with immediacy. Electronic portfolio systems may or may not include assessment delivery, accepting, and/or analysis features.

\section{Communication and Collaboration}

The ability to engage in critical discourse through e-learning endeavors has been shown to benefit the learning process (Sweat-Guy, 2006). Electronic portfolio systems may include features that allow students to send and receive messages, engage in chats and discussions, share information, and collaborate.

\section{Course Management}

Some electronic portfolio systems include a course management component, others work in conjunction with an existing course management system, and some are stand alone products. When course management is a built-in feature, it commonly includes the ability to deliver learning materials, the online submission of assignments, an electronic grade book, and a discussion forum.

\section{Evaluations/Observations}

Although this feature is more commonly found in electronic portfolio programs geared towards pre-service teacher education, several portfolio systems offer the ability for the creation, acceptance, and calculation of forms internship supervisors/employers and academic supervisors to complete online evaluations of student performance in pre-professional internships.

\section{Hosting and Storing of Information}

Some electronic portfolios are hosted by individual academic institutions whereas others are hosted by a paid service provider. When the system is hosted by the individual academic institution costs are usually lower and there may be more opportunities for customization; however, it becomes the responsibility of the adopting institution to support and update the system. When the system is hosted by the system producer all support and updates are provided.

\section{Intended User and User Type}

The intended users vary among portfolio systems which may be geared towards government agencies, not-for-profits, teacher education programs, and/or general higher education use. Within individual institutions the platform may be built to accommodate the needs of students, faculty, and or administrators.

\section{Learning Outcomes}

Most individuals in the assessment community believe that the assessment process begins with the identification of learning goals and measurable outcomes (Martell \& Calderon, 2005) as well as the use of specific traits that help define the outcomes being measured (Walvoord \& Anderson, 1998). Frequently electronic portfolios allow students to present a collection of items that repre- 
sent their accomplishments towards the satisfaction of either pre-determined or student- authored learning outcomes.

\section{Reflections}

Chun (2002) explains that the portfolio building process encourages students to engage in structured reflection as well as to see how learning translates into productive practice. Commonly, electronic portfolios include a mechanism for students to author and submit meaningful reflections where they explain why each artifact was chosen and which learning goal it satisfies or represents.

\section{Reporting}

Capabilities for reporting for accreditation and validation purposes is a common electronic portfolio feature and may include data collected and aggregated from rubrics, portfolios, student placement tests, diagnostic tests, grades, advisement information and participation in university activities, use of remediation services, technology use, attendance, and other useful information (Dhir, 2005).

\section{Rubrics}

According to Aurbach \& Associates (1999), rubrics articulate the standards by which a product, performance, or outcome demonstration will be evaluated. They help to standardize assessment, provide useful data, and articulate goals and objectives to learners. Rubrics are also particularly useful in assessing complex and subjective skills (Dodge \& Pickette, 2001). Petkov and Petkova (2006) who implemented rubrics in an introductory IS courses found that the use of rubrics helped to make assessment more uniform, better communicate expectations and performance to students, measure student progress over time, and help to lay the foundation for a long-term assessment program that combines projects and portfolios. Rubrics are the most prevalent method for evaluating electronic portfolios (Buzzetto-More \& Alade, 2006).

\section{Sharing of Information}

Electronic portfolios are often evaluated using a team of assessors (Buzzetto-More \& Alade, 2006). They are frequently also used by students for professional promotion. As a result, electronic portfolios often give students and/or faculty the ability to invite multiple individuals within and outside of the institution to review and comment on the portfolio.

\section{Surveys}

Surveys are often used as part of an assessment program in order to gauge the opinions of current students, recent graduates, alumni, cooperating institutions, and/or employers. Several electronic portfolio systems include the mechanism for the dispersion, collection, and/or analysis of online surveys.

\section{Templates}

A variety of learning objectives may be found within electronic portfolio systems. The most common learning objectives include templates or the ability to build templates for the inputting of resumes, field experience evaluations, lesson plans, and etcetera. Additionally, this area is commonly facilitated by a database whether existing, customizable, or buildable of national, state, local, professional, and or other standards. 


\section{Technological}

According to Jafari (2004) characteristics of successful e-portfolio systems include: ease of use; a plan for technological sustainability, growth and maintenance; robust integrated technology architecture; long-term accessibility to users; the potential to add new technology features over time; and the $\mathrm{X}$ factor. Jafari defines the $\mathrm{X}$ factor as unknown attributes that emerge over time that will enhance the overall usefulness of the system. Other considerations identified by Butler (2006) include: linkage of reflections to artifacts; technical standards; file formats accepted; system security; scalability; coding language; accessibility; support; privacy; accessibility; portability; reportability; organization; interoperability; and data analysis.

\section{Common Publicly Available Electronic Portfolio Platforms}

There are a variety of attributes or features that may influence the adoption of an electronic portfolio system. Some features will rank higher in importance than others and it is up to the individual institution to develop a long range plan for the use of an electronic portfolio system that takes into account the desired outcomes for both students and student learning assessment. Below are eight examples of common publicly available platforms. This section will be followed by a matrix that offers a side by side comparison of the platforms considered compared against select features discussed in the previous section.

\section{ePortfolio}

ePortfolio is an authoring, learning audit and analysis system that facilitates student learning portfolios, the online delivery of learning materials, external field work assessment, and resume and portfolio distribution (via e-mail, intra-server, and downloadable external storage). The system provides multiple user editable templates for the creation of multiple electronic portfolios through the import of files. It also supports career and academic counseling through the advisor assessment role; supports non-rubric assessments which can be aggregated and disaggregated; links interventions to multiple standards; and provides an editable database of standards that can be linked to artifacts, cross referenced, and tabled. To enhance the assessment capabilities it can be bundled with a rubric maker which will support the creation and aggregation of rubric data completed by multiple assessors.

Users can securely share portfolios with peers, groups, or external e-mail recipients. Additionally, members of the faculty and institution can share documents as "common artifacts" with students. Security options are provided and can be combined (time lapsed URLs, aliased URL, or passwords required by viewers). ePortfolio reports performance across students by median, mean, mode, standard deviation, largest changes, overall average and detailed standards (shows $\%$ having reached selected levels of performance and raw scores for achievement for selected standards). All reports can be aggregated and disaggregated and given user defined demographic filters. Additionally, ePortfolio provides individual, team, and system-wide tracking, analysis, and reporting of learning activity and results.

It is intended to be used by institutions of higher education, K-12 schools, government agencies, and the business sector. It includes such communication tools as discussions, email, and chats; but not blogs, wikis, or a message board. It also supports internship evaluations.

Chalk \& Wire, the host company, provides permanent storage of all work samples submitted for assessment and dedicated server options. With one option, servers are fully hosted and co-hosted (site institution). With the second option, Chalk \& Wire will fully host all aspects of the service using an Internet Provider Service to protect and deliver data and a statistically significant sample 
of all archived assessment work samples. The pricing for higher education depends on the number of accounts which ranges from $\$ 10$ - \$22 per student for a four month contract and \$49$\$ 90$ for a four year contract. For K-12 school the pricing structure is per site per year and ranges from $\$ 95-\$ 318$ depending on the number of sites. The basic support package for new institutions is prices at $\$ 2,900$.

\section{Foliotek}

With the Web-based Foliotek, students have the ability to: (a) import artifacts supported by a variety of file types; (b) align elements of their portfolios with standards and objectives applicable to their program and/or institution; (c) perform a gap analysis on their portfolio so they can see which standards might require further attention; and (d) create multiple portfolios to showcase and share with others through an online invitation process. The collaboration tool allows online messaging and comments integrated with e-mail for students and faculty within designated groupings and within the system. Additionally, portfolios can also be shared with peers to receive additional comments on artifacts; the online announcement tool allows program administrators to post announcements on student homepages; and internship evaluations can be created and submitted.

Foliotek allows users to structure portfolios around standards and objectives and supports online assessment with scoring rubrics built around standards. Student demographics, experiences, and academic progress are among the data collected. Online surveys can be administered to current students and alumni and the data collected can be exported to MS Excel or ASCII text format for use in other systems for statistical analysis. Academic advisement, template creation, resumes, discussions, and blogs and wikis are not supported.

The intended user is K-12 schools and institutions of higher education. Foliotek hosts and manages the system and has developed several pricing options. A 6 year student account can be purchased for $\$ 125$, with this pricing structure there is no cost to the University. If the University would like to reduce the cost for students, program fees of $\$ 3,000-\$ 5,000$ approximately per year reduces the cost of the 6 year account to $\$ 96$. A license transfer fee of $\$ 2,000$ (portfolio design) is charged to institutions converting from a pricing schedule with no institutional fees to a pricing schedule with institutional fees.

\section{LiveText}

Designed for use in higher education primarily in pre-service teacher education, LiveText is a Web-delivered subscription service for teachers and teacher candidates that supports student portfolios, lesson plan building, and the delivery of learning materials and resources linked to U.S. national, state, and local standards and facilitates step-by-step templates for developing lesson plans. LiveText is the application service provider that manages the hardware, administers the server and provides firewall protection.

For faculty, document templates are available for creating course syllabi, reference materials, student assignments, student assessments, quizzes, discussion boards and handouts, all of which multimedia may be embedded. LiveText allows faculty to create and share lesson plans, projects, courses, or portfolios with colleagues, giving them the ability to review or adapt materials using a real-time sticky note feature that saves to the original document. It includes an assessment feature that supports the creation of assessments that can be used by a course, program, department, college and university. In addition to formal assessments, LiveText offers reviewers the opportunity to post comments and provide annotations on submitted materials.

Administrators and faculty can identify, align, and report standards by course, program, department or university, as well as, integrate standards into portfolios, course assignments, and assessments. It also features a large repository of standards and benchmarks. The service allows 
users to exhibit standards usage reports online or export data to another application. Additionally, an Exhibit Center has been created that enables administrators and faculty to accumulate and present evidence for reporting and accreditation purposes such as program syllabi, course outcomes, student coursework, and student/faculty portfolios, with the ability to customize how documents are presented, grouped, and reported.

LiveText's form building tool supports the creation of questionnaires and surveys that can only be distributed internally. It does not support student advisement, chats, blogs, wikis, message posting, internship evaluations, and resumes.

Students can create presentation portfolios with a series of style templates that can be reviewed with a LiveText Visitor's Pass or exported for personal or departmental archiving. LiveText is available to students for a membership term of $\$ 89.00$. A membership term is valid for the entire time a student is registered and enrolled in an educational institution, plus an additional year after graduation. After graduation, the student may renew membership on a yearly basis.

\section{TaskStream}

TaskStream's target market extends to individuals, higher education, secondary and elementary schools, content providers, business \& Industry, government agencies, and not-for-profits. It provides the means for a group of subscribers within an organization to submit work to other members of the organization for review and/or evaluation. Additionally, multiple portfolio types are supported.

TaskStream's assessment methods include rubrics, surveys, write-in scores, meets/does not meet requirement, and pass/fail. Requirements, evaluations, roles, and permissions can be designed and administered. As work is started, submitted, and evaluated, its status is tracked and made available to participants and administrators and the assessment system supports multiple evaluations for a single submission and reconciliation capabilities. TaskStream offers instructional design tools that include: a standards database, competency database; a tool that allows users to design, assemble, and sequence a series of learning activities as well as create design templates; and a rubric wizard that aggregates. This system also offers resource management and communication tools: that include management and storage capabilities of individual work; downloadability; internal e-mail system; online instant messaging system; discussion board; announcements; and a calendar. TaskStream's reporting capabilities manage, aggregate, and present assessment data. It does not support chats, blogs, wikis, academic advisement, and/or internship evaluations.

TaskStream is hosted by the company and accessed online. Subscriptions are available for years 1 thru 6 at a rate of $\$ 39, \$ 65, \$ 85,499, \$ 111$, and $\$ 120$, respectively with no cost to the adopting institution.

\section{Tk20}

Tk20 is an assessment system used to deliver e-learning as well as mentor and assess teachers in $\mathrm{K}-12$ education or teacher education candidates. Tk20 is customizable to support the conceptual framework, artifacts, standards, rubrics, portfolios, transition points, surveys, and reports of the college. Students can create and submit standards-based reflective portfolios that are assessed by one or multiple faculty members, individually or collaboratively using customizable rubrics and assessment instruments and all data related to portfolios can be viewed as customized reports. Users can also export their portfolios to a CD-ROM for personal and/or professional use.

The company that offers this product imports data from student information systems to set up course shells for instructors. Course websites include internal and external communications via an e-mail system, assignments submission and analysis, assessments, a grade book, syllabi and other document posting, and the management of teaching assistants. All course-based activity is man- 
aged through templates and, once built, templates can be reused for other courses in the same or other semesters. Artifacts are can be assessed individually and also grouped into a portfolio. Tk20 includes a message board but does not support chats, discussions, blogs, or wikis.

This platform provides the means for documenting candidate field experiences as well as customizing and collecting data for recording, aggregating and reporting. Field experience artifacts are set up to document activities, location, the name of the cooperating teacher and the university supervisor. Additionally, teacher education candidates can record the demographics and composition of the students and any other relevant information. Candidates can create reflective journals about field experiences and receive feedback. Additionally, the system can be customized to contain a list of cooperating schools and teachers.

Academic advisors are provided with information about candidates' academic progress and program requirements and can determine further requirements making notations to candidate advisement records.

Surveys can be created and distributed to faculty, students, and graduates that include text answers, multiple choice questions, and Likert scale forms. Built-in reports support the viewing of survey results as answers are automatically collated and aggregated. Surveys can be scheduled for launch and automatic reminders can be set. All data associated with course-based activity can be combined with other data in the system for reporting. Additionally, survey and other data can be imported and exported from other systems, and an exhibit room allows the grouping of documents for demonstrating artifacts during accreditation reviews.

Tk20/HigherEd is a licensable system that is hosted by the institution. It is available at a onetime fee of $\$ 10,000$ that does not include the cost of the server but includes customization, reporting support and maintenance upgrades for the life of the system. Student users are required to pay a one-time fee of approximately $\$ 100$ for use of the system, typically for seven years.

\section{TrueOutcomes}

TrueOutcomes supports student portfolios, faculty-controlled assessments, curriculum records, and surveys. It is designed for institution-wide implementation, customized to serve different disciplines, and can be used by student services, counseling, food services, housing, and other offices that impact the quality of student life.

Student portfolios are a password protected, collection of academic and co-curricular work that students own and maintain that can be accessed over the Web or saved to a disk to hand out at career fairs and interviews. The portfolios can be assessed through rubric-based evaluation where teams of faculty and/or external stakeholders evaluate the assignments using rubrics. The evaluation and data from the portfolio reviews are reported and charted.

TrueOutcomes' survey module separates demographic information from survey opinion questions to preserve anonymity. Response scales are created using a form that allows for both quantitative and qualitative responses. It can be used for course evaluation, student/alumni/employer surveys, focus groups, and exit interviews. The data is analyzed in real time where graphs and tables are presented and can also be exported for further analysis. The Curriculum Record is the faculty's plan for developing educational outcomes and a log of changes made. Faculty enter descriptions of assignments and corresponding activities that support the development of educational outcomes. This information is used to generate a matrix of courses vs. outcomes by academic major, along with a chronological report of curricular changes and justification for changes. The performance assessment module can be used for local or nationally-normed exams, rubric-based evaluation of student work, capstone project/senior thesis review, and other direct measures of 
student performance. Program-level assessments and reports can be generated showing the curriculum plan, student achievement against standards, and a record of changes to the curriculum.

Faculty and administrators can aggregate the portfolios of groups of students or alumni for examination of curricula and assessment of educational outcomes to identify where in the curriculum the outcomes are developed. TrueOutcomes stores student demographic information and tracks student history while it collects evidence of learning mastery. The software comes with a library of standards, rubrics, and survey questions that can be customized. It is designed to be used in higher education and does not support discussions, chats, blogs, wikis, messaging, or lesson plans.

TrueOutcomes is a $100 \%$ Java based licensed platform and must be hosted by the academic institution. The cost depends on the number of users and the level of support needed; however, the exact price structure was unavailable to these researchers.

\section{Blackboard Portfolio Platform}

In 2005, the two leading course management system providers Blackboard and Web-CT merged. During the summer of 2006 they piloted their joint portfolio system which entered the market fall 2006. The Blackboard/Web-CT Electronic Portfolio System is designed to compliment the Blackboard and Web-CT virtual course environments. The user interface has a similar layout and employs similar tools that can be found with these popular course management systems with adjustments made to support portfolio creation and presentation. This is not a stand alone product but rather is an add-on that cannot be used without prior adoption of one of the course management systems.

Graded material from online courses can be imported directly into portfolios. Templates for entire portfolios can be created as well as additional templates to be used within portfolios for such activities as resume building.

The students serve as portfolio owners who have control over the material, design, and membership of their portfolio. Users create presentation portfolios that showcase a collection of their accomplishments, evaluations, and reflections in a Web-based environment. The system supports a variety of file types and allows for multiple artifacts and includes an internal html creator. Artifacts can be linked to personal learning goals created by students or course/program goals preestablished by instructors. Teaching standards at the national, state, and/or local level are not included. Students can alter their portfolios for different viewers, invite and dis-invite assessors and guests internal and external to the institution, and allow people to give feedback. Students can create and refine learning goals as well as author public and private reflections, discussions, and blogs.

Rubrics can be created within the LMS component despite the fact that rubric aggregation is not a planned functionality. Surveys can also be distributed and aggregated through the CMS but are exclusive to individuals enrolled in individual courses and are not designed to be distributed outside the institution. Quizzes are created using the survey tool and can be distributed through the CMS.

Academic program advisement is not available only portfolio progress checklists exist and field experience observation forms are also not supported within the portfolio. Limited reporting capabilities are offered, whereas all reporting is at the individual portfolio level. The list of available reports include: summary of activity, item usage, file use, and reviewer tracking. Additionally, for institutions already using a Blackboard product this system allows for shared system administration and does not require separate installation. It is designed to serve institutions of higher education where it is commonly hosted and supported by the institution and located on an institutional 
server. The minimal license term for the portfolio product is 12 months, which for 2006-2007 is $\$ 20,900$. Although not listed in the pricing structure, usage is dependent on the prior adoption and purchase of a Blackboard CMS.

\section{Open Source System}

Open Source Portfolio Initiative (OSPI) began in January, 2003. The OSP Initiative's community is comprised of educational institutions, foundations, corporate investors and government agencies. The current activity-based features of the application include the Portfolio Studio, the Resource Tool (which is the result of combining Sakai resource tool with the OSP repository tool from previous versions), and the Report Designer.

The Portfolio Studio is where the student creates portfolios using the portfolio designer or predefined templates. The portfolio designer allows the student to customize multi-pages using selective layouts and styles. This page also allows the student to manage all portfolios. The Resource Tool, which is displayed using a filing system of folders and sub-folders, allows the portfolio owner to collect, access, store, and organize data and digital items such as audio, video, and documents. The resource tool consists of the wizard page which contains guidance, forms, feedback, and evaluation items. The wizard page also supports reflective activities of the portfolio owner by providing tailored reflection forms and guided reflection activities. The Report Designer allows administrators, coordinators, and course instructors to generate reports using a fillin report definition prompter. The results can be exported to other software applications such as Microsoft Word and Excel.

OSP enables students, faculty, and administrators to collaborate and exchange ideas between and among each other. Course instructors can also provide feedback, formative and summative evaluations, and comments. A set of terms and definitions are provided system-wide via the glossary. The OSP supports an environment that is inclusive of national and international standards.

OSP does not have all of the features that can be commonly found in the more commercially available products mentioned previously; however, because the source code is accessible, features can be built and added overtime at the discretion of an individual institution.

Technically, OSP runs on a server and can be accessed via any Web browser. OSP has the capability to operate as a stand alone portfolio system or it can be interfaced with other course management systems, human resource, student information, learning management, and other enterprise-wide systems. OSP encourages open standards and specifications. Students are able to save their portfolios using removable media.

The OSP software is free; however, there are discriminating cost factors such as the hardware, installation, support staff, training, customization, application hosting, and the integration with other systems just to name a few.

\section{Conclusion}

While the notion of using portfolios as assessment tools is not new, many disciplines are just beginning to explore the advantages of electronic portfolios. Electronic portfolios are a unique way to document student progress, encourage improvement and motivate involvement in learning (Buzzetto-More, 2006). When thoughtfully implemented the benefits are numerous, serving a number of purposes and stakeholders (ePortConsortium, 2003).

There are any number of considerations that may influence the electronic portfolio adoption decision-making process. Uses, needs, and stratagem may vary and some features may be more important than others. As a result, when choosing an electronic portfolio system it is important to 
identify the following: the future users and uses, the desired benefits, whether the system will also serve as an online course management and delivery tool, technology requirements, cost, and what features are necessary to serve institutional/departmental objectives. To assist in this process, Jafari (2004) recommends the creation of a long-range plan that takes into account implementation, sustainability, and current and future needs.

This paper has provided an examination of flexible and sophisticated systems for evaluating collections of student work for the purpose of outcomes assessment. This paper does not propose to tell schools what they should require of an e-portfolio system; rather it has been designed as an unbiased report of popular e-portfolio platform features to help inform the decision making process. Following in Table 1 is a matrix that provides a side-by-side comparison of the features of the electronic portfolio platforms discussed in this paper compared against select features discussed earlier.

\begin{tabular}{|c|c|c|c|c|c|c|c|c|}
\hline & 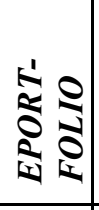 & 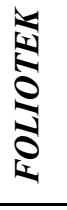 & 辣 & 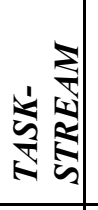 & 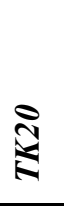 & 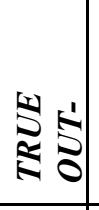 & 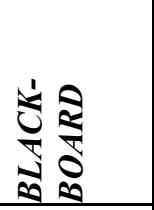 & 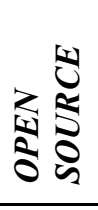 \\
\hline Advisement & $\checkmark$ & & & & $\checkmark$ & $\checkmark$ & & $\checkmark$ \\
\hline Artifacts (Multiple File Types) & $\checkmark$ & $\checkmark$ & $\checkmark$ & $\checkmark$ & $\checkmark$ & $\checkmark$ & $\checkmark$ & $\checkmark$ \\
\hline Assessment Quizzes/Exams & $\checkmark$ & $\checkmark$ & $\checkmark$ & $\checkmark$ & $\checkmark$ & $\checkmark$ & $\checkmark$ & \\
\hline Collaboration & $\checkmark$ & $\checkmark$ & $\checkmark$ & $\checkmark$ & $\checkmark$ & $\checkmark$ & $\checkmark$ & $\checkmark$ \\
\hline Communications & $\checkmark$ & & $\checkmark$ & $\checkmark$ & & & $\checkmark$ & \\
\hline Cost Paid Through Site License & $\checkmark$ & & & & $\checkmark$ & $\checkmark$ & $\checkmark$ & \\
\hline Costs Paid Through Student Fees & & $\checkmark$ & $\checkmark$ & $\checkmark$ & $\checkmark$ & & & \\
\hline Course Management and Delivery & $\checkmark$ & & $\checkmark$ & $\checkmark$ & $\checkmark$ & $\checkmark$ & $\begin{array}{c}\checkmark \\
\begin{array}{c}\text { Prior Adoption } \\
\text { Dependent }\end{array}\end{array}$ & $\checkmark$ \\
\hline Evaluation/Internship Observation & $\checkmark$ & $\checkmark$ & & & $\checkmark$ & $\checkmark$ & & \\
\hline Hosted By Institution & $\checkmark$ & & & & $\checkmark$ & & $\checkmark$ & $\checkmark$ \\
\hline Hosted By Company & $\checkmark$ & $\checkmark$ & $\checkmark$ & $\checkmark$ & & $\checkmark$ & & $\checkmark$ \\
\hline User K-12 Schools & $\checkmark$ & $\checkmark$ & & $\checkmark$ & $\checkmark$ & & & \\
\hline User Higher Education & $\checkmark$ & $\checkmark$ & $\checkmark$ & $\checkmark$ & $\checkmark$ & $\checkmark$ & $\checkmark$ & $\checkmark$ \\
\hline User Government/Corporate & $\checkmark$ & & & $\checkmark$ & & & & \\
\hline
\end{tabular}




\begin{tabular}{|c|c|c|c|c|c|c|c|c|}
\hline \multicolumn{9}{|c|}{ TABLE 1: A COMPARISON OF COMMON ELECTRONIC PORTFOLIOS MATRIX } \\
\hline & 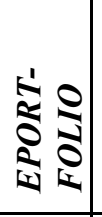 & $\frac{\sqrt[3]{3}}{3}$ & $\underset{7}{5}$ & 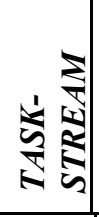 & $\underset{\mathbb{N}}{*}$ & \begin{tabular}{l}
$\mathfrak{s}$ \\
\hdashline \\
\hdashline \\
\hdashline
\end{tabular} & 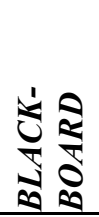 & 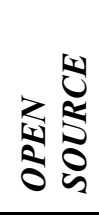 \\
\hline Learning Outcomes/Goals & $\checkmark$ & $\checkmark$ & $\checkmark$ & $\checkmark$ & $\checkmark$ & $\checkmark$ & $\checkmark$ & $\checkmark$ \\
\hline Multiple File Types Supported & $\checkmark$ & $\checkmark$ & $\checkmark$ & $\checkmark$ & $\checkmark$ & $\checkmark$ & $\checkmark$ & $\checkmark$ \\
\hline Reflections & $\checkmark$ & $\checkmark$ & $\checkmark$ & $\checkmark$ & $\checkmark$ & $\checkmark$ & $\checkmark$ & $\checkmark$ \\
\hline Reporting & $\checkmark$ & $\checkmark$ & $\checkmark$ & $\checkmark$ & $\checkmark$ & $\checkmark$ & & $\checkmark$ \\
\hline Rubrics & $\checkmark$ & $\checkmark$ & $\checkmark$ & $\checkmark$ & $\checkmark$ & $\checkmark$ & $\checkmark$ & $\checkmark$ \\
\hline Surveys Distributed Internally & $\checkmark$ & $\checkmark$ & $\checkmark$ & $\checkmark$ & $\checkmark$ & $\checkmark$ & $\checkmark$ & \\
\hline Surveys Distributed Externally & $\checkmark$ & $\checkmark$ & & $\checkmark$ & $\checkmark$ & $\checkmark$ & & \\
\hline
\end{tabular}

\section{References}

Abrenica, Y. (1996). Electronic portfolios. Retrieved 4/14/06 from http://edweb.sdsu.edu/courses/edtec596r/students/abrenica/abrenica.html

American Association for Higher Education. (2001). Electronic portfolios: Emerging practices for students, faculty and institutions. Retrieved from http://aahe.ital.utexas.edu/electronicportfolios/index.html

Anderson, R. S. \& DeMeulle, L. (1998, Winter). Portfolio use in twenty-four teacher education programs. Teacher Education Quarterly, 25(1), 23-31.

Aurbach and Associates. (1999). The teacher's portfolio. Retrieved from http://www.aurbach.com

Barrett, H. C. (2000). Create your own electronic portfolio. Learning and Leading with Technology, 21(7), 14-21.

Barrett, H. C. (2004). Differentiating electronic portfolios and online assessment management systems. Proceedings of the SITE Conference. Retrieved from http://electronicportfolios.com/portfolios/SITE2004paper.pdf

Bartell C. A., Kaye, C., \& Morin, J. A. (1998, Winter). Portfolio conversation: A mentored journey. Teacher Education Quarterly, 25(1), 129-139.

Batson, T. (2005, July 7). The current state of e-portfolios in higher education. Educause Live. Retrieved from: Http://www.educause.edu/live0513.

Butler, P. (2006, October). A Review of the literature on portfolios and electronic portfolios. Retrieved from: https://eduforge.org/docman/view.php/176/1111/ePortfolio\%20Project\%20Research\%20Report.pdf

Buzzetto-More, N. (2006). The e-Learning and business education paradigm: Enhancing education, assessment, and accountability. Proceedings of the Maryland Business Education Association Conference. Ocean City, MD.

Buzzetto-More, N., \& Alade, A. (2006). Best practices in e-assessment. Journal of Information Technology Education, 5, 251-269. http://jite.org/documents/Vol5/v5p251-269Buzzetto152.pdf 
Chun, M. (2002). Looking where the light is better: A review of the literature on assessing higher education quality. Peer Review. Winter/Spring.

Cooper, T. (1999). Portfolio assessment: A guide for lecturers, teachers and course designers. Perth: Praxis Education.

Dhir, K. (2005). Content access and the use of data for student learning: The case of Berry College. In K. Martell \& T. Calderon, Assessment of student learning in business schools: Best practices each step of the way (Vol. 1, No. 2, pp. 167-183). Tallahassee, Florida: Association for Institutional Research.

Dodge, B., \& Pickette, N. (2001). Rubrics for Web lessons. Retrieved 2/12/06 from http://edweb.sdsu.edu/webquest/rubrics/weblessons.htm

ePortConsortium.Org. (2003). Electronic Portfolio White Paper [Version 1.0]. Retrieved 4/14/06 from http://eportconsortium.org

Haken, M. (2006). Closing the loop-learning from assessment. Presentation made at the University of Maryland Eastern Shore Assessment Workshop. Princess Anne: MD.

Hamilton, D. \& Shoen, E. (2005). Same song, second verse: Evaluation and improvement of an established assessment program. In K. Martell \& T. Calderon, Assessment of student learning in business schools: Best practices each step of the way (Vol. 1, No. 2, pp. 138-153). Tallahassee, Florida: Association for Institutional Research.

Jafari, A. (2004). The sticky e-portfolio system: Tackling challenges and identifying attributes. Educause Review, 39(4), 38-49.

Lorenzo, G. \& Ittelson, J. (2005a). An overview of e-portfolios. Educause Learning Initiative Paper 1: 2005.

Lorenzo, G, \& Ittelson, J. (2005b). Demonstrating and assessing student learning with e-portfolios. Educause Learning Initiative Paper 3:2005.

Love, T. \& Cooper, T. (2004). Designing online information systems for portfolio-based assessment: Design criteria and heuristics. Journal of Information Technology Education, 3, 65-81. Available at http://jite.org/documents/Vol3/v3p065-081-127.pdf

Martell, K., \& Calderon, T. (2005). Assessment of student learning in business schools: Best practices each step of the way. Association for Institutional Research, 1(1-2), 1-22.

Montgomery, L.A. (2002). Electronic portfolios for pre-service teachers: Merging technology, selfassessment, and reflective practice. Paper presented at the American Association of Colleges for Teacher Education Conference, New York City.

National Council for Accreditation of Teacher Education (NCATE). (1997). Technology and the new professional teacher: Preparing for the 21st century classroom. Retrieved 4/10/05 from:

http://www.ncate.org/projects/tech/TECH.HTM

Office of Research Education (OERI). (1993a, November). Consumer guide: Student portfolios: Classroom uses. Retrieved 4/14/06 from: http://www.ed.gov/OR/ConsumerGuides/classuse.html.

Office of Research Education (OERI). (1993b, September). Consumer guide: Performance assessment. Retrieved 4/14/06 from: http://www.ed.gov/OR/ConsumerGuides/perfasse

Page. D. (2006). 25 tools, technologies, and best practices. $T$ H E Journal, 33(8). Retrieved from http://thejournal.com/articles/18042

Paulson, F. L., Paulson, P. R., \& Meyer, C. (1991). What makes a portfolio a portfolio? Educational Leadership, 48(5), 60-63.

Petkov, D. and Petkova, O. (2006). Development of scoring rubrics for IS projects as an assessment tool. Issues in Informing Science and Information Technology Education. 3, 499-510. Available at http://informingscience.org/proceedings/InSITE2006/IISITPetk214.pdf 
Popper, E. (2005). Learning goals: The foundation of curriculum development and assessment. In K. Martell \& T. Calderon, Assessment of student learning in business schools: Best practices each step of the way (1(2), pp. 1-23). Association for Institutional Research.

Ridgway, J., McCusker, S., \& Pead, D. (2004). Literature review of e-assessment. Bristol UK: Nesta Future Lab.

Sweat-Guy, R. (2006). Investigating the effects of instructional strategies and communication modes on interaction in an online environment: Findings from a pilot study. Proceedings of the Global Business Digital Review Conference. Las Vegas, NV.

Walvoord, B. E., \& Anderson, V. J. (1998). Effective grading: A tool for learning and assessment. San Francisco: Jossey-Bass.

Weidmer, T. (1998). Digital portfolios: Capturing and demonstrating skills and levels of performance. Kappan. 79(8).

Wright, B. (2004, October 1). An assessment planning primer: Getting started at your own institution. Presentation Made at the $13^{\text {th }}$ Annual Northeast Regional Teaching Workshop.

\section{Biographies}

Dr. Retta Sweat-Guy has an Ed.D. in Curriculum and Instruction with emphasis in Instructional Systems Design from the University of Kentucky. She received her masters in Public Administration from Kentucky State University and a Bachelor of Arts degree in Business Education from the University of Kentucky. Currently, she is Assistant Professor in the Department of Marketing and Business Education at Fayetteville State University in Fayetteville, North Carolina. Online teaching and learning serves as the basis for her current research for which she has presented at conferences and referred publications. She has and continues to conduct workshops and training sessions on the uses of web-based course management tools. She has published several book chapters and is currently working on her first fully authored book.

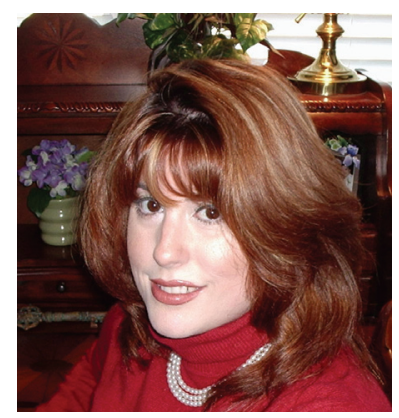

Dr. Nicole A. Buzzetto-More is an Assistant Professor, Business Education program coordinator, and Assurance of Learning coordinator in the Department of Business, Management, and Accounting at the University of Maryland Eastern Shore. She is also Co-Founder of the UMES Office of Instructional Technology. She received doctorate and masters degrees in communication and instructional technology from Columbia University and also holds degrees from the College of New Rochelle and Marist College. As a recognized assessment and elearning expert, she is a frequent presenter at conferences across the globe. She is on the editorial board of several journals, has authored numerous publications in referred journals, and has been recognized with an award from the American Distance Education Consortium. Her two books published in early 2007, Principles of Effective Online Teaching and Advanced Principles of Effective E-Learning, are available through the Informing Science Press. She is currently working on her third book. 